\title{
El papel político del ejército en los países de Asia y Africa*
}

GUEORGUI MIRSKI, doctor en Ciencias Económicas, es director del Departamento de estudios sociales y políticos de los paises subdesarrollados del. Instituto de Economía Mundial $Y$ Relaciones Internacionales de la Academia de Ciencias de la Unión Soviètica.

Es autor de varios libros, entre ellos Ejército y politica en el Tercer Mundo (1969).

La acentuación que se observa en los últimos tiempos del papel de las fuerzas armadas en la política de los países en desarrollo, los golpes de Estado militares, que se hicieron más frecuentes, y la implantación de regímenes militares en varios países no puede menos que suscitar un comprensible interés hacia el problema de la incorporación del ejército al ámbito político en Asia y en Africa. Según sea la orientación política de los autores, suele denominarse al ejército del "Tercer Mundo" ya bien fuerza motriz de la revolución, clase nueva, representante de las "nuevas capas medias", o agente del imperialismo. En cualquier caso, no se objeta el hecho de que el ejército goza de cierta autonomía, ni la tendencia a convertirlo en una fuerza política más o menos independiente.

La cuestión del grado de posible autonomía del ejército está vinculada con un problema más general: con la posibilidad de una independencia, aunque sólo sea provisoria y relativa, del Estado rẹspecto de la sociedad en los países que están en proceso de tránsito del régimen colonial a la nueva vida. El análisis de las obras de C. Marx y F. Engels dedicadas a la doctrina sobre el Estado, da fundamento para deducir que los fundadores del marxismo, luego de hacer por primera vez en la historia la definición del Estado como instrumento del predominio de clase y de haber dilucidado su naturaleza explotadora en la sociedad que se basa en la propiedad priva-

*El presente artículo fue publicado también en la Revista Ciencias Sociales Conlemporáneas, $\mathrm{N}^{\circ}{ }_{5}, \mathrm{M}$ oscú, 1969 . 
da sobre los medios de producción, establecieron al mismo tiempo que en esa sociedad al poder estatal le es inherente la tendencia inmanente a alienarse de la sociedad que lo ha engendrado, a superponerse a ella y a ser relativamente independiente de la misma ${ }^{1}$. Esta tendencia puede ponerse de manifiesto en un período de transición del desarrollo de la sociedad o en el empalme de dos épocas, cuando las clases principales acusan un equilibrio relativo o debilidad.

Por ejemplo, analizando la esencia del Segundo Imperio en Francia, G. Marx dejó constancia de que el poder estatal se había hecho "independiente de la propia sociedad", que había comenzado a pisotear "incluso los intereses de las clases dominantes"2. ¿En interés de quién funcionaba esa máquina independiente, apoyada en el aparato militar? Objetivamente, según lo demostrara C. Marx, en interés de las clases propietarias y, en primer lugar, del pequeño propietario rural, y también de la burguesía urbana. Pero no sería justo considerar que la máquina bonapartista estaba simplemente al servicio de estas clases. Bonaparte "se ve obligado - escribía C. Marx- a crear, junto a las clases reales de la sociedad, una casta artificial, para la que el mantenimiento de su régimen es un problema de cuchillo y tenedor..."s. La máquina ya ha emprendido su marcha independiente, e incluso la clase económicamente dominante puede constituir para ella cierto peligro: los intereses corporativos del aparato burocrático militar no consienten el reparto del poder, sólo el monopolio del poder puede garantizar a esta casta la estabilidad de su posición, la firmeza de sus privilegios y asegurarle el "cuchillo y tenedor".

En la sociedad basada en el dominio de la propiedad privada, el ejército es un sector de la burocracia: la burocracia militar. Por eso la tendencia a la alienación respecto de la sociedad y al predominio sobre la misma - propia del aparato burocrático en general, y advertida por C. Marx y F. Engels- es innata también en plena medida al ejército.

Por eso, aplicado al Segundo Imperio, C. Marx escribía en los Esbozos para "La guerra civil en Francia" del "poder estatal que encontró su expresión última y suprema" y que "pisotea incluso los intereses de las clases

${ }^{1}$ Véase, por ej., C. Marx y F. Engels: "El dieciocho Brumario de Luis Bonaparte", Obras escogidas (en dos tomos), Moscú, 1966, t. I. pp. 316-317; Ibid, t. II, pp. 318-319, 321.

${ }^{2}$ C. Marx y F. Engels. Obras, Moscú, t. 17 , p. 545 (en ruso).

${ }^{3}$ C. Marx y F. Engels: "El dieciocho Brumario de Luis Bonaparte", ed. cit., t. I, p. 323. 
Gueorgui Mirski / El papel politico del ejército en los paises de Asia y Africa dominantes". C. Marx se refería precisamente al predominio del ejército, que se guiaba por sus intereses propios $y$, en aras de ellos, era capaz de alzarse contra la clase dominante. Desde el punto de vista objetivo, naturalmente, ese ejército era burgués y en el momento decisivo defendía los intereses de la burguesía, pero en un determinado lapso histórico, debido al equilibrio de fuerzas de las clases en pugna, ocupó algo así como la posición de árbitro.

También F. Engels señalaba refiriéndose a la independencia provisional del poder estatal $y$ de la burocracia en Francia, que la capacidad del ejército de desempeñar un papel independiente y decisivo no sólo es indirecta, sino también directa. Por ejemplo, refiriéndose a Alemania: "El ejército se convirtió una vez más en la fuerza decisiva del Estado"4,

No es éste el único caso en que F. Engels se refiere al ejército como a una fuerza decisiva. En su trabajo "El papel de la violencia en la historia", escribia: "En la política sólo existen dos fuerzas decisivas: la fuerza organizada del Estado, el ejército y la fuerza no organizada, espontánea de las masas populares". La experiencia de la revolución proletaria triunfante en Rusia demostró que el éxito puede lograrse cuando la primera de estas fuerzas - el ejército- ya no puede o no quiere defender al viejo Estado, instrumento de opresión de clase; y la segunda, la fuerza espontánea, se convierte en organizada bajo la dirección del partido.

Muchos ejemplos históricos testimonian que en circunstancias de inestabilidad política y de disturbios o en un período de cambios sociales, el ejército desempeña el papel de fuerza autónoma. El historiador soviético S. Utchenko demostró que "en las condiciones de la realidad política romana, es decir, no existiendo partidos políticos en el sentido contemporáneo de la palabra, dándose un estado de desmoralización entre la plebe de las ciudades y de indiferencia política por parte de la población rural, el ejército podía ser el único baluarte seguro, desempeñando hasta cierto punto el papel de la organización política más consolidada". César lo comprendió así. "César, desilusionado de la "democracia" romana y sin considerarla un apoyo seguro, en el lugar de esa fuerza política vetusta y ya ineficaz, puso con absoluta conciencia a una nueva organización social-politica: al

\footnotetext{
${ }^{4}$ C. Marx y F. Engels. Obras, Moscú, t. 8, p. 6I (en ruso).

${ }^{5}$ C. Marx y, F. Engels. Obras, Moscú, t. 21, pp. 446-447 (en ruso).

${ }^{6}$ S. Utchenko: Crisis y caida de la República romana, Moscu, 1965, p. 197 (en ruso).
} 

ejército romano"7. Se sobrentiende que no puede hacerse una analogía total con la situación en los países en desarrollo. Los ejércitos de los países liberados del predominio colonial tienen un doble carácter, precisamente porque aún no se ha agotado la función antimperialista y emancipadora del Estado, del cual estos ejércitos son instrumento.

En los paises en desarrollo el ejército no es simplemente "una copia de la sociedad", ni simplemente una suma aritmética de tal o cual número de descendientes de campesinos, de la pequeña burguesía, etc. En el servicio militar todos estos "descendientes" adquieren una calidad nueva, se aglutinan en un organismo nuevo. El ejército adquiere los rasgos de una corporación con sus propios intereses. Toda organización aislada y cerrada corre el peligro de fecundar el espíritu de casta, de aislarse de la sociedad, de convertirse en un mecanismo independiente. El ejército no es una excepción. La solidaridad profesional puede convertirse en corporativismo y éste pasa fácilmente al espíritu de casta. La orgullosa conciencia de pertenecer a una profesión "elegida" puede transformarse en un complejo de superioridad en relación con los "civiles".

El científico francés B. Vernier escribe en su trabajo El ejército y la política en el Medio Oriente: "En la antigua sociedad tradicional, el militar no se diferenciaba de la masa. No pertenecía a un cuerpo especial ni a un "grupo" separado. Naturalmente que muchos guerreros salían del orden común y conquistaban tronos, pero se trataba de sus éxitos personales que no cambiaban la estructura del mundo en que vivían. El medio normal de escalamiento no era la carrera de las armas, sino la carrera del hombre de derecho, de la religión... Hoy ya todo es diferente"s. El ejército, escribía el diario libanés Orient, se convirtió en el medio de ascenso social.

El ejército se distingue por la cohesión, la disciplina y la centralización del mando. Lo principal, por supuesto, consiste en que el ejército dispone de armas, es decir, del medio para intimidar y para emplear la fuerza. A medida que crece el pertrechamiento técnico de las fuerzas armadas - tanto del ejército como de la policía-, ese medio se hace más amenazante. EI poderío de las fuerzas armadas es hoy mucho mayor que en la época en que los soldados sólo estaban armados con fusiles. Los medios gobernantes de los países del "Tercer Mundo" se dan perfecta cuenta de ello.

${ }^{7}$ Ibidem.

B. Vernier: Armée et politique au Moyent Orient, París, 1966, p. 220. 
Gueorgui Mirski / El papel político del ejército en los países de Asia y Africa

En los últimos tiempos, se acentuó en mucho el papel del ejército en el sentido de mantener "la seguridad interna". Por cuanto esta "seguridad" no es una categoría militar sino militar-política, puede decirse que con ello incrementó la eficacia del ejército precisamente como factor político, o, para ser más exactos, como factor de la política interna. Esta circunstancia, de la que tienen conciencia los oficiales y generales de los países asiáticos y africanos, no podía dejar de incidir en el sentido del papel que desempeñan en la sociedad, de sus ventajas y' posibilidades políticas. La institución de la sociedad que toma conciencia de su superioridad sobre otras en la medida en que el ejército toma conciencia de su superioridad sobre todas las organizaciones políticas y estatales, no puede evitar la tentación de "tomar las cosas en sus manos". En la revista Rinascita, órgano del Partido Comunista Italiano, se indica: "En una sociedad económicamente atrasada... un ejército privilegiado, separado del cuerpo social del país, constituye la fuerza más relevante y única, por lo menos, dotada de una estructura vertical eficiente y de una homogeneidad social y cultural. Una fuerza con la que no puede compararse ninguno de los grupos políticos existentes, comprendidos los dominantes... una fuerza político-social autónoma, independiente del aparato estatal y del gobierno. Esta fuerza es la más moderna y eficiente de las que actúan en el país, precisamente porque está libre de toda condicionalidad política, tiende inevitablemente a asumir en primera persona una iniciativa propia que supedita a las propias exigencias inmediatas, corporativas de todo el cuerpo social; y menoscaba incluso las preocupaciones estratégicas de los grupos económicos dominantes".

A nuestro juicio, la formulación del autor italiano precisa ser especificada. "La heterogeneidad del ejército" es un concepto relativo. Es sabido que los ejércitos en los países de Asia y Africa distan de ser heterogéneos. Además, tambièn se sabe que existen otras organizaciones militarizadas. El punto de vista del autor, en lo concerniente a la plena libertad del ejército respecto de la "condicionalidad política", induce a particular objeción.

Incluso si el ejército, en virtud de determinadas causas del desarrollo histórico.del país dado, obtiene cierta autonomía de acción, se "aísla" de la sociedad y persigue sus intereses corporativos especiales (que se reducen fundamentalmente a defender su situación privilegiada, a consolidarla y garantizarla frente a cambios no deseables para él).

${ }^{9} \mathrm{~L}$. Castellina: "La Grecia il giorno dopo", Rinascita, 5 Maggio Ig67. 
E S T U D I O S I N T E R N A C I O N A L E S

¿Significa-acaso que con ello no refleja objetivamente los intereses de clase alguna? No hay más que una respuesta: en cualquier caso, el ejército contribuye objetivamente a una vía de desarrollo socioeconómico, lo cual responde a los intereses de una clase concreta o de determinadas clases. Recordemos, por ejemplo, que el régimen de Luis Bonaparte, que era independiente y parecía pisotear incluso los intereses de la burguesía, según lo demostrara C. Marx, expresaba objetivamente los intereses de determinadas clases, incluso del agricultor pequeño propietario. En este caso, no tenía la menor importancia que la cúspide militar burocrática, y tanto más el propio Emperador, subjetivamente no tuvieran con ese campesino nada en común ni pensaran en él en lo más mínimo. Lo importante era otra cosa: la política económico-social del régimen bonapartista correspondía, en general, a los intereses del pequeño propietario agrícola y conservaba las condiciones que conjuraban su desiintegración.

Al llegar al poder el ejército se dedica a la actividad estatal práctica; de ese modo, voluntaria o involuntariamente, consciente o inconscientemente, lleva a cabo la línea del desarrollo económico-social que responde a los intereses de unas clases y contradice a los de otras.

En los países en desarrollo el ejército puede convertirse en una fuerza que contribuya tanto al desarrollo capitalista como al no-capitalista, lo cual no tanto depende de las intenciones subjetivas de sus jefes como de las condiciones que se dan en la sociedad. La independencia del ejército respecto de la sociedad disminuye considerablemente — como se verá más adelante-, precisamente cuando aquél llega al poder $y$, diríase, logra plena libertad de acción.

El análisis de decenas de golpes de Estado militares acaecidos en los últimos dos decenios en los países de Asia, Africa y Aimérica Latina permiten hacer ciertas deducciones y tratar de establecer las leyes que los rigen.

Tanto a los ejércitos en su totalidad, como a las acciones políticas que ellos realizan, les son propios ciertos rasgos formales no vinculados directamente con el carácter de esos ejércitos y de esas acciones. Del mismo modo que cualquier ejército - no importa a quién sirva - tiene su jerarquía de grados, una disciplina militar, juramento, reglamento, etc., la ingerencia del ejército en la política y su llegada al poder son operaciones que revisten, podría decirse, un carácter profesional y poseen los rasgos inherentes al 
Gueorgui Mirski / El papel politico del ejército en los paises de Asia y Africa ejército, independientemente de quiénes sean los beneficiados de esas operaciones.

Examinemos primeramente la variante del golpe de Estado militar "clásico", es decir, el alzamiento de un sector de la oficialidad, al frente de unidades militares, con la finalidad de derrocar al gobierno (a diferencia del levantamiento de todo el ejército por orden del comandante en jefe). ¿Qué grado de unanimidad entre los militares se requiere para el éxito del golpe?

La situación de los conspiradores siempre es difícil. Por un lado, cuantas menos personas tengan conocimiento del complot, tanto mayor seguridad hay. Mas por otro lado, cuanto mayor número de militares prometan con antelación su apoyo, tanto más fácil sería llevar a cabo el golpe y tanto mayores serían las posibilidades de éxito. El ejemplo de varios putschs fracasados en Siria, Irak, Ghana y otros países confirma que para que un golpe de Estado militar se corone con el éxito no basta con el simple alzamiento de una unidad militar aislada, ni siquiera si ésta se posesiona de la capital $y$ anuncia haberse apoderado del poder. Por lo común, Ios insurrectos quieren tener de su parte a los comandantes de las armas, o aunque sea a algunos de ellos, $y$, por lo menos, contar con el apoyo de los jefes de las guarniciones $y^{*}$ agrupaciones de tropas más numerosas en las que está concentrado el grueso de las fuerzas armadas. Esos jefes deben estár al corriente del complot y aprobarlo, o deberá existir la seguridad de que no se negarán a apoyar el golpe cuando se dé. Para uno u otro caso es importante que en la mente de la mayoría de los oficiales que ocupan los puestos clave haya madurado la idea de que hay que derrocar al gobierno. A su

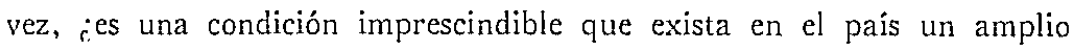
descontento nacional con el régimen?

Recurramos a ejemplos históricos. En Egipto en I 952, Irak en $195^{8}$ y I 963 , Yemen en 1962, Pakistán en 1958, Birmania en 1962 , Turquia en ig6o, Sudán en 1958 , Nigeria en 1966 , Siria en 1961 y 1963 , había un indudable descontento con los regímenes vigentes en esos países exteriorizado desde la pasividad y la desilusión hasta las manifestaciones activas de las masas. Todos los sistemas políticos de los Estados enumerados, en el momento de los golpes militares, ya habían madurado, en mayor o menor grado, para caer. Por lo menos, la opinión pública ya les había negado definitivamente su confianza y era de esperar que el golpe fuera aprobado por la población. 
No se dio un solo caso en que el ejército diera un golpe de Estado con éxito (a pesar de existir el apoyo de la mayoría de oficiales que ocupaban los puestos clave, lo cual, como hemos visto, garantiza la prosperidad del golpe), cuando el gobierno se encontraba en la cima de la popularidad y gozaba del apoyo incuestionable de la población.

Esto implica que el terreno para el golpe no madura en el ejército, sino en la sociedad. Otra cosa es que el terreno puede madurar y, sin embargo, continuar rigiendo el gobierno en el país. Son numerosos tales ejemplos en los países de Asia y Africa.

El ejército reacciona con bastante sensibilidad a los cambios que se producen en el estado de ánimo de la opinión pública. Precisamente por el hecho de que para el éxito del golpe militar se requiere la solidaridad o el consentimiento - aunque sólo sea tácito- de los jefes que ocupan los puestos clave. Prácticamente se excluye la posibilidad de que algún general ambicioso se apodere del poder por su cuenta y riesgo sin tomar en consideración la situación y la opinión pública: no lo apoyarán otros jefes militares y el putsch fracasará. Por eso, durante el golpe de Estado el elemento de casualidad o de aventura es mucho menor de lo que puede suponerse. Por lo visto, debe existir cierta opinión colegiada secreta de los oficiales que ocupan los puestos decisivos en cuanto a que es deseable cambiar el poder. Cuanto más elevado es el nivel en el que se organiza el complot, más convincentes pueden ser los argumentos en favor del mismo $y$ tanto mayor puede ser la seguridad de que el golpe se verá coronado con el éxito y será apoyado. Porque los jefes militares superiores no sólo son mayores en edad $y$, por consiguiente, más cautelosos que los jóvenes, sino pueden perder mucho más, pues ya tienen asegurada una alta posición. Pero los oficiales jóvenes, por lo general, tampoco quieren arriesgar su posición ni su vida si no existen motivos realmente serios para pronunciarse contra el gobierno. Es cierto que debe hacerse esta reserva: si los oficiales están persuadidos de que las autoridades civiles piensan hacer cambios en el ejército, es decir, si ven que su propia situación está en peligro, pueden dar un golpe preventivo, como ocurrió en varios países de Asia y Africa.

¿Puede considerarse que los militares, una vez apreciada la situación $y$ sopesadas las probabilidades en pro y en contra del golpe, sólo toman en consideración la opinión pública nacional? En primer lugar, si, pero no sólo eso. El descontento general por uno u otro régimen suele ser habitualmente muy vago e indeterminado por cuanto confluyen en él distintos matices 
Gueorgui Mirski / El papel político del ejército en los paises de Asia y Africa del descontento de clase y grupo. Por ejemplo, aunque por motivos opuestos, a principios de 1966 estaban descontentos del régimen de Hafez en Siria, tanto los estratos burgueses como los de izquierda. A principios de I 963 , en Irak casi todos estaban descontentos de Kassem, pero los motivos eran los más diversos.

Si el complot lo dirige una organización militar revolucionaria, se orienta, naturalmente, hacia el sector radical de izquierda de la opinión pública, como tuvo lugar en Egipto, en Sịra y otros países. Pero cuando la iniciativa del golpe no le pertenece a una organización política dentro del ejército, con un programa social determinado, aunque sea en estado embrional, sino que le pertenece a los jefes superiores de las fuerzas armadas que, por regla general, están educados en un espíritu burgués conservador, éstos toman en cuenta, fundamentalmente, la opinión de la "clase media", es decir, de los medios burocráticos y burgueses moderados. Asi ocurrió, por ejemplo, en Sudán, en Pakistán y también en Ghana.

En la mayoría de los casos, el golpe de Estado lo dan personas que ya ocupan cierta posición (y con mayor frecuencia bien destacada) en el mismo sistema político que piensan derrocar (o cambiar). Así por ejemplo, por lo común dirigen los golpes de Estado (especialmente en los últimos tiempos), los mandos superiores de las fuerzas armadas, los comandantes de armas, de ejércitos, de circunscripciones militares. Las acciones emprendidas por algunos jefes militares revisten más bien el carácter de Fronda, de tentativa de modificar la correlación de fuerzas en el propio ejército o de influir en la composición y la política del gobierno, que el carácter de un golpe militar "total". Cabe hacer una diferencia entre estos tipos de pronunciamientos políticos de las fuerzas armadas. No debe considerarse cada ingerencia del ejército en la política como un intento de subir al poder.

En 1962 en Birmania, en 1958 en Pakistán, en 1965 en Indonesia, en $195^{8}$ en Sudán, en r 966 en Nigeria y en 1960 en Turquía, el ejército tomó el poder. por orden de los jefes superiores de las fuerzas armadas. El golpe de Estado de $195^{8}$ en Irak fue realizado directamente por los jefes de dos brigadas seleccionadas. En los países de Africa tropical, por regla general, los golpes son también dados por los comandantes en jefe de las fuerzas armadas. Mas en Egipto, en $195^{2}$, la iniciativa del golpe partía de la oficialidad media, pero en este caso Nasser y sus partidarios tampoco estaban al margen del mismo. Eran personas conocidas y respetadas en el ejército: a Nasser, en particular, 
E S T U D I OS I N T E R N A C I O N A L E S

lo conocía la mayoría de los oficiales egipcios porque era profesor de táctica en la Academia Militar.

Las causas de los golpes de Estado pueden agruparse del siguiente modo:

1. la existencia en el país de un amplio descontento, principalmente de carácter nacionalista, por la política insuficientemente autónoma o abiertamente prooccidental de la cúspide gobernante que no desea ni tiene capacidad para Ilevar a cabo las reformas sociales ya maduras en un clima en el que se carece de. una oposición civil fuerte y organizada al régimen. Este fue el factor principal en Egipto y en Irak;

2. una crisis política interna crónica, resultado de la incapacidad del gobierno civil para resolver los problemas internos ya maduros y para sacar al país de un callejón sin salida;

3. el descontento de la élite culta por la rutina y el arcaísmo de un régimen despótico (por ejemplo, en Yemen);

4. la ineficacia general de la administración civil, combinada con la corrupción administrativa, con la apatía y la desilusión de las masas y el terror de la cima privilegiada ante la perspectiva de que se consoliden las fuerzas de izquierda y la posibilidad de una revolución popular (Pakistán, Turquía, Sudán). En este caso, no se trata de un "golpe de los coroneles", sino de un putsch de generales tendiente a conservar los rasgos sociales primordiales del sistema anterior implantando un régimen de "mano dura".

En algunos países de Asia y Africa contribuyen a los golpes de Estado militares también los siguientes factores:

I. una guerra perdida; después de la catástrofe de Palestina, por ejemplo, Siria y Egipto atravesaban una dura crisis moral; el ejército se sentía traicionado por los líderes civiles; el poder había perdido su prestigio;

2. una guerra civil demasiado dilatada a la que no podía dar solución el gobierno anterior; el peligro de que se desintegrara el Estado multinacional (Birmania);

3. acentuación del papel del ejército como resultado de las represiones militares de los gobiernos precedentes contra las minorías nacionales u otros insurrectos (las operaciones militares del ejército iraquí contra las asirios, los kurdos y los campesinos sublevados en los años precedentes a la serie de golpes de Estado militares, es decir, antes de I956).

Por el carácter de la organización, los golpes de Estado pueden dividirse en dos tipos fundamentales: 
Gueorgui Mirski / El papel político del ejército en los paises de Asia y Africa

1. todo el ejército toma el poder por orden del mando y el golpe reviste el carácter de una operación de las fuerzas armadas, pero no en la esfera militar, sino en la política. Por lo común, los militares se subordinan a la orden, pues de lo contrario significaria una infracción de la disciplina militar;

2. un sector del ejército, encabezado por un grupo de oficiales conspiradores, se pronuncia con el objetivo de derrocar al gobierno $y$ 'de remover el mando militar, ya que éste es leal al gobierno. Desde el punto de vista del gobierno y del mando militar, eso es un motín. Los militares, al apoyar un golpe de esta indole (a diferencia del primer caso), violan la disciplina militar, participan en un motín, y en consecuencia, arriesgan su vida. Es fácil adivinar qué suerte habrían corrido Nasser, Kassem y Al-Sallal si sus golpes de Estado hubieran fracasado. La ejecución de los oficiales conspiradores del ejército de Ghana, después de un frustrado intento de golpe de Estado en 1967 , la ejecución de dos coroneles en Turquía después de una tentativa análoga en 1964 y otros ejemplos, son una prueba elocuente de que los oficiales que no sólo se alzan contra el gobierno, sino también contra el mando superior, no pueden esperar clemencia.

Estos dos tipos esenciales de golpes de Estado tienen muchas variaciones. En cuanto a su contenido político, no tiene relación con el propio carácter de la organización del golpe. Ne Win, Ayub Khan, Abboud, Gürsel, Mobutu y Onganía actuaron casi igualmente en cuanto a la forma: liquidaron la administración civil en nombre de las fuerzas armadas en su totalidad y en nombre del pueblo.

El ejército no es una fuerza extraclasista ni supraclasista. Los ejércitos egipcio, iraquí o birmano servían antes de la revolución los intereses de la cúspide burguesa terrateniente. Pero el ejërcito está vinculado con la sociedad, y los de los países citados, integrados fundamentalmente por representantes del pueblo trabajador, no quedaron al margen de las necesidades e intereses de éste en un clima de creciente crisis interna y de contradicciones de clase cada vez más exacerbadas. De un modo latente se operaba el proceso de cambios en la conciencia de los militares, el proceso de bifurcación de esa conciencia. La revolución tuvo lugar primeramente en la conciencia de los militares: la idea revolucionaria los había conquistado. Comenzó la preparación del golpe. El ejército, permaneciendo 
E S T U D I O S I N T E R N A C I O N A L E S

exteriormente como instrumento de la vieja cúspide privilegiada, ya se convertía en su fuero interno en fuerza de la oposición, dispuesta a violar el juramento. $Y$ cuando se dio el golpe de Estado, ya fuera en Egipto o en Irak, no lo había hecho el ejército como tal, dirigido por su generalato, sino la organización revolucionaria dentro del ejército que había removido a la jefatura anterior del mismo. En Birmania las cosas se dieron de otro modo y la toma del poder revestía el carácter de una acción emprendida por el ejército propiamente dicho por orden del comandante en jefe, en nombre del Consejo Revolucionarionario. Mas Ne Win, como es notorio, no había comenzado su carrera como militar profesional, sino como patriota revolucionario, y el propio ejército birmano era revolucionario y había surgido en el curso de la lucha contra los colonizadores.

La organización revolucionaria dentro del ejército pudo conquistar en Egipto $y$ en Irak una rápida y fácil victoria y apoderarse del poder, porque era la vanguardia política consciente del ejército en su totalidad. En efecto, ¿qué fuerza impulsó a los oficiales que no participaban en el complot o no sabían nada de él a adherirse de inmediato a los sublevados? :Qué incitó a los comandantes de las circunscripciones militares $y$ de las guarniciones provinciales a negar su apoyo a la monarquía, a la que habian rendido juramento, y prestárselo a los revolucionarios? De no haber sido por el apoyo de esos comandantes, el golpe hubiera fracasado a pesar de haber sido ocupada la capital; se conocen numerosos ejemplos de intentos de golpes de Estado en Irak y en Siria que fracasaron incluso después de haberse tomadio el poder en la capital, porque los comandantes de otras circunscripciones y guarniciones se negaron a apoyar a los rebeldes. Las preguntas hechas sólo tienen una respuesta: la idea revolucionaria había madurado en la mente de los militares, había madurado en el ejército en su totalidad, excepto en un puñado de altos generales. En estos casos siempre aparece una vanguardia que marcha de cara al riesgo y arrastra a los demás. Por eso no se debe considerar que los golpes de Estado a los que nos referimos fueron dados por una organización militar revolucionaria contra la voluntad de todo el ejército. Sólo se dieron contra la voluntad de un puñado de generales que habian unido su destino a la monarquía.

Una vez tomado el poder, se plantea la cuestión: ¿qué hacer más

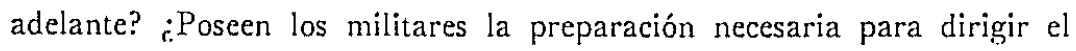
Estado? Sin duda alguna los generales de la generación mayor, los profesionales de las escuelas inglesa o francesa, como Abboud en Sudán, carecieron 
Gueorgui Mirski / El papel político del ejército en los paises de Asia y Africa de esa preparación. Personas como él podían encarcelar a los funcionarios más comprometidos, establecer el orden en las calles, pero no estaban en condiciones de ponerse al frente de la magna lucha por la superación del atraso y la formación de un nuevo Estado desarrollado; además, habían arraigado demasiado en la cúspide burocrática burguesa. ¿Pero puede incluso la joven oficialidad revolucionaria manejar un país apoyándose tan sólo en el aparáto del ejército? El general Ne Win, por ejemplo, indicaba que ni un solo hombre de su gobierno — ni siquiera él一 poseía en la esfera económica los suficientes conocimientos para dirigir una empresa comercial estatal tan gigantesca ${ }^{10}$. Un oficial de carrera, por regla general, sólo puede ser un administrador expeditivo, pero en la mayoría de los casos sólo en el nivel inferior o medio. El patriotismo, la fidelidad al deber, la voluntad, la decisión, la disciplina y el espíritu de organización son todos factores insuficientes cuando no se trata simplemente de poner orden, sino de una labor complicadísima y paciente, imprescindible para hacer una reestructura cardinal de las relaciones sociales en los países de Asia y Africa recientemente liberados del yugo colonial.

Janowitz ${ }^{11}$ escribe que si el objetivo politico de primer orden consiste en convencer y no en la coerción, para juzgar sobre la eficacia de la oligarquía militar en el frente interno hay que guiarse por el criterio de la capacidad que tengan los militares para crear una base política de masas o para permitir que ésta surja.

Después de tomar el poder, ante el régimen militar se plantea la tarea de asegurar la dirección política nacional. Si los militares quieren lograr esta finalidad politica, deben constituir un aparato político de masas con capacidad vital, al margen de su propia estructura orgánica, pero un aparato que se encuentre bajo su influencia decisiva.

Una vez establecido el orden, sostiene E. Shills ${ }^{12}$, a los militares ya casi no les queda nada que hacer para imbuirse de seguridad en sí mismos $y$ causar impresión en la opinión pública. Este autor estima que existe el peligro de que queden suspendidos en el vacío, relleno tan sólo con adelantos tales como un gobierno limpio y calles aseadas. Shills dice que los milita-

${ }^{10} \mathrm{FEYU}$ Quarterly Economic Review, Continental South East Asia, 1966. N.4, p. 4 .

${ }^{11} \mathrm{~J}$ anowitz: The Wilitary in the Political Development of New Nalions, Chicago 1964.

${ }^{12}$ E. Shills: The Military in the Political Development of the New States, en el libro: The Role of the Military in Underdeveloped Countries, Princeton, 1962. 
res no son negociantes ni funcionarios públicos con ideología de desarrollo económico. Si estimulan a cualquiera de estos dos grupos o a los dos simultáneamente, debilitarán ellos mismos sus posiciones, permitiendo que se formen centros independientes de poder $y$ de definición de una orientación. Pero si no estimulan o no consienten la actividad de los grupos independientes, en el país se producirá un estancamiento.

La esencia del dilema al que se refiere E. Shills reside en lo siguiente: el viejo aparato, formado aún en tiempos de los colonizadores, no puede corresponder a los requisitos de la nueva etapa de la revolución; en el mejor de los casos, puede garantizar el cumplimiento de los asuntos corrientes, el trabajo de la máquina administrativa. El nuevo aparato, llamado a realizar las tareas revolucionarias, debe ser político y estar penetrado de una determinada ideología. Pero precisamente en virtud de ello, tal aparato tendrá ciertas ventajas en el sentido de su influencia sobre la opinión pública ante los militares, cuyo poder, en la mayoría de los casos, carece de una carga ideológica. Sin una organización política, permaciendo en el vacio, el régimen militar no podrá existir largo tiempo: necesita apoyarse en las masas. Porque el régimen militar es producto de un golpe de Estado y está al margen de la legalidad; al principio sus méritos se reducen a asestar golpes al viejo régimen desacreditado. Pero ese arrebato inicial no puede durar mucho tiempo. Si el régimen militar carece de un eje político, de un programa constructivo y de una ideología que movilice a las masas, será estéril, yermo y vacio por dentro. Mas al permitir que se desarrollen las fuerzas politicas y que se cree una organización de masas con su plataforma ideológica, el régimen militar se arriesga a iniciar el camino de su autoaniquilación lenta, pero irremisible.

En nuestra época, en los países en desarrollo los regímenes militares como tales (es decir, los de una dictadura puramente militar) no pueden tener capacidad de vida por un período más o menos largo: son demasiado trascendentales y urgentes las tareas que se plantean ante esos países. Los regimenes militares ya bien deben modificarse, o sea, convertirse en regimenes sociales con una base de masas, una organización política y una ideologia, o bien abandonar la escena. No es casual que la dirección militar revolucionaria de la RAU, Argelia, Siria y Birmania traten de movilizar la actividad de las masas y crear de este modo una amplia base para su poder, que traten de organizar y consolidar un partido de vanguardia. En realidad, estos regímenes ya comienzan a perder su carácter militar. 
Gueorgui Mirski / El papel político del ejército en los países de Asia y Africa

Pero convertir los regímenes militares en sociales dista de ser simplemente una labor de organización, tendiente a "asentarse" en una u otra base política de masas. Naturalmente que el régimen militar, al tener noción de su debilidad, busca con frecuencia una base sólida y permanente para si, $y$ este es un factor muy importante para comprender la situación política constituida en los países que atravesaron golpes de Estado. El régimen busca una base, y con ello busca un apoyo social para sí. Lo instan a ello una serie de factores tanto de orden interior como exterior, $y$, ante todo, la necesidad de garantizar el fomento económico del país, de apoyarse en alguien en la lucha contra los enemigos exteriores e interiores y de conservar su poder. El último ejemplo de esta indole es la evolución del régimen de Mobutu. Mas el régimen militar, incluso contando con una autonomía de acción bastante extensa y con un amplio campo para maniobrar, no está, pese a ello, enteramente libre en la elección de su orientación. El propio carácter de la base que sondea lo determina, en gran medida, la génesis de ese régimen, sus relaciones sociales y la actitud que ha adoptado hacia las diferentes fuerzas sociales ya en la primera etapa de su gestión e incluso antes del golpe.

El investigador argentino Torcuato S. di Tella llama la atención hacia el factor del grado de alienación de los militares respecto del régimen precedente en cuyo seno maduró la decisión de incorporarse a la política. Di Tella observa con razón que cuanto más honda es la alienación, más fuerte es la tendencia de incorporar a los militares a la lucha por cambios de fondo en el sistema vigente, $y$ cuanto más débil es, más probabilidades hay de que todo se limite a un golpe de Estado militar corriente ${ }^{13}$. Llevando esta idea más adelante, puede decirse que el carácter del influjo al que se ven sometidos los militares antes del golpe, en el período de la formación de sus conceptos políticos, ya predetermina en gran medida su línea política después del golpe. Pero el carácter de esa influencia depende del clima político general en el país.durante la agudización de los conflictos sociales. La fuerza y la profundidad de la decisión de los militares no sólo para dar un golpe de Estado, sino para hacer cambios radicales de estructura es, por lo común, directamente proporcional al grado de candencia de la lucha politica en el país, del grado de descontento de la sociedad por el régimen

${ }^{13}$ T. S. di Tella, G. Germani, J. Graciarena, Argentina, Socierlad de Masas, Buenos Aires, 1965, p. 282 . 
E S T U D I OS I N T E R N A C I O N A L E S

anterior, del nivel desarrollo del pensamiento revolucionario entre la intelectualidad civil, que suministra ideas y la plataforma política a los militares.

- Isí por ejemplo, en visperas de $195^{2}$ en Egipto existía un hondo abismo entre la cúspide real en bancarrota, definitivamente desacreditada y la opinión pública, cuya expresión era la intelectualidad políticamente muy desarrollada, con una orientación muy de izquierda, pero que no tenía una organización. Los "oficiales libres" hicieron suyas de inmediato las más importantes ideas del arsenal ideológico de esa intelectualidad. El régimen anterior no había resuelto los problemas cardinales, $y$, en primer término, el agrario $y$ el del retiro de los imperialistas ingleses, de modo que los líderes militares tuvieron que afrontar esos problemas sin pérdida de tiempo, $y$ ello, a su vez, predeterminó en cierta medida la actitud que adoptara. hacia ellos tanto la reacción nacional como la internacional, contribuyendo a que la formación de sus conceptos siguiera una orientación radical.

- partir de la década del 30 la atmósfera social en Birmania estaba penetrada de ideas antimperialistas y democráticas, $y$ luego socialistas, que formaban parte del arsenal de la ideología oficial; también había una corriente marxista. En el período de preparación para la toma del poder, el programa de los oficiales revolucionarios fue elaborado bajo el influjo indudable de esa ațósfera. En Siria los jóvenes oficiales que llegaron al poder en I 966 trazaron su plataforma partiendo de la ideología oficial del partido Baàs y no prescindieron de las ideas del socialismo científico. En estos dos casos los revolucionarios militares "se apoderaron" de la bandera ideológica que estaba en manos de la intelectualidad radical civil, en un clima en que la última era incapaz de lograr que los gobiernos burgueses reformistas pusieran en práctica los principios de izquierda, en lugar de hacer malabarismo con consignas socialistas para sus fines demagógicos. Históricamente la situación se configuró de tal modo que la vanguardia de la intelectualidad con espiritu progresista, la que expresaba los intereses de las masas, resultó lllevar uniforme militar, sin dejar por ello de ser la vanguardia de un determinado movimiento politico $y$ no una fuerza independiente cualquiera que se cocía en su propia salsa. La "alienación" de este movimiento respecto de los regímenes que habían llegado a un callejón sin salida resultó ser lo suficientemente profunda como para comunicar un carácter radical a la orientación ideológica de la vanguardia y de incitarla a realizar transformaciones sociales de fondo. 
Gueorgui Mirski / El papel político del ejército en los paises de Asia y Africa

"Lo que hace el ejército -observa Leo Hamon- no solamente depende de lo que es el propio ejército, sino también —en mayor medida-del resto, $y$ en ese resto debe incluirse el pasado de una sociedad y de un Estado"14.

En varios países, donde en virtud de las particularidades del desarrollo histórico no habia un movimiento democrático fuerte $\mathrm{e}$ influyente (Tailandia, la mayoría de los países de Africa tropical), o donde ese movimientó había fracasado (Indonesia, Ghana), los militares obtuvieron la posibilidad de gobernar - por un determinado período histórico- sin contar con un apoyo firme en las masas, sin la ayuda de un movimiento político de masas, sin una ideología que mereciera este nombre en lo más mínimo y sin un programa elaborado de transformaciones económico-sociales. En estos países los militareș gobiernan la sociedad $y$ le imponen su dominio en interés propio, aunque objetivamente se trata de los intereses de las clases privilegiadas. Aspiran a prolongar la existencia de los regimenes militares, pues para ellos, repitiendo a Marx, es una cuestión del "cuchillo y tenedor". Su interés inmediato es la autoconservación y autorreproducción.

Mas desde el punto de vista objetivo, en la mayoría de eșos Estados la casta militar burocrática contribuye al desarrollo de las relaciones capitalistas. Esta casta se diferencia muy poco de la burguesía burocrática que detenta el poder en una serie de países, $y$, en primer lugar, en Africa tropical.

A la vez, cabe señalar que en varios países de Asia y de Africa (Egipto, Siria, Birmania, Argelia) el ejército desempeñó un papel notabilísimo en la lucha por la independencia nacional, estuvo al frente de esa lucha, $y^{\prime}$ luego de la emancipación participó en el cumplimiento de una política orientada a realizar transformaciones sociales de fondo. En estos países los lideres democrático-revolucionarios que proclamaron el programa de edificación de una sociedad socialista proceden de la oficialidad del ejército y las masas populares tienen en muy alta estima el papel revolucionario del ejército.

No obstante, la realidad confirma que el ejército no puede ser por siempre la fuerza motriz de la revolución social ni la vanguardia política de la sociedad y remplazar al partido político. La constitución de un partido

${ }^{14}$ Le role extra-militaire de l'Armée dans le Tiers Monde, editado por Leo Hamon, PuF, Paris, 1966, p. $3^{86 .}$ 
E S T U D I OS I N T E R N A C I O N A L E S

de vanguardia, fiel a la causa de la edificación del socialismo, es la condición obligatoria para el desarrollo consecuente y feliz del país por las vías no capitalistas, que sólo en este caso y contando con un clima internacional propicio puede llevar a la etapa de la edificación del socialismo en todos los frentes.

El espíritu derrotista del sector burgués aristocrático de la oficialidad egipcia en los días de la agresión israelí en junio de $1967 \cdot y$ el complot contrarrevolucionario de la "burguesía militar" en la RAU no debe considerarse como algo casual. Por lo visto, la ausencia de control del ejército profesional en los países económicamente atrasados, su relativa autonomía, la aspiración del generalato a dominar sobre la sociedad sin supeditarse a ella, son los rasgos que facilitan su transformación en corporación burocrática, con conceptos burgueses. Las tendencias antirrevolucionarias y antidemocráticas, condicionadas por el deseo de conservar la posición privilegiada de la oficialidad como una corporación, como una élite, se ponen vivamente de manifiesto en la etapa en que se despliega la revolución social. Tan sólo un partido de vanguardia, que se atenga a una ideología auténticamente socialista, puede contribuir a convertir el ejército en la fuerza armada realmente popular, libre del espíritu de "élite" y de casta. 